\title{
A PRODUÇÃO ACADÊMICA EM POLÍTICAS EDUCACIONAIS PARA EDUCAÇÃO INFANTIL NO BRASIL (2005-2010)
}

\author{
Manuela Monteiro dos Santos Macêdo'; Faní Quitéria Nascimento Rehem²; \\ 1. Bolsista PROBIC/UEFS, Graduando Licenciatura em Pedagogia, Universidade Estadual de Feira de Santana, e- \\ mail: manu_hta33@yyahoo.com.br \\ 2. Orientador, Departamento de Educação, Universidade Estadual de Feira de Santana, e-mail: \\ fanirehem2@gmail.com
}

PALAVRAS-CHAVE: Política Educacional; Produção Acadêmica; Educação Infantil.

\section{INTRODUÇÃO}

O presente trabalho cujo título é A produção acadêmica em políticas educacionais para educação infantil no Brasil (2005-2010) tem por objetivo mostrar a configuração das defesas de teses e dissertações apresentadas nos cursos de pósgraduação em educação no Brasil através da análise das"características epistemológicas e metodológicas, e identificar as principais tendências dessa produção, indicando possíveis contribuições e lacunas em relação às perspectivas de constituição do campo de estudo em políticas educacionais". A base utilizada para análise foi uma pesquisa anterior que organizou um banco de dados com 1.283 teses e dissertações entre $2000 \mathrm{e}$ 2010 em políticas educacionais coletadas no banco de teses da Centro de Aperfeiçoamento de Pessoal do Ensino Superior - CAPES. Para tanto dialogamos com os seguintes referências, Kuhlmann Jr (1998); Rocha (1999), Arce (2001), Ferreira (2002), Hofling (2001), Marli André (2001), Penn (2002), Rosemberg (2002), Arretche (2003),Shiroma, Campos e Garcia (2005), Gatti (2001), Krawczyk (2012), Rehem (2013), Silva (2016), e Silva e Jacomini (2016),os quais têm discutido e problematizado sobre a educação infantil e políticas educacionais.

\section{MATERIAL E MÉTODOS OU METODOLOGIA}

A pesquisa é de caráter delimitado como "Estado da Arte" ou "Estado do Conhecimento", que por sua abrangência propicia uma visão das discussões que tem ganhado destaque nas produções acadêmicas no Brasil. Segundo Romanowski e Ens (2006) estudos como este possibilitam a organização dedados sobre uma área de conhecimento, bem como aponta lacunas e possíveis rupturas sociais.A abordagem é de natureza qualitativa que, embora tenha por base a quantidade de produção das discussões no campo das políticas educacionais para educação infantil, a ênfase recai na qualidade dos resumos tomando como direção as abordagens teóricas sobre o tema.

O material utilizado é proveniente de uma pesquisa maior que traçou o quadro das produções em políticas educacionais em âmbito nacional.Na organização do banco de dados utilizamos como forma de seleção as seguintes características: ano de defesa e Instituição de Ensino Superior (IES), número de teses e dissertações (mestrado e doutorado), região de localização da IES e número de trabalhos por estado, além da análise e classificação dos resumos,a qual necessitou-se da definição dos seguintes descritores: Infantil, Infância e Creche. A pesquisa utilizou como critério de análise os trabalhos de programas de pós-graduação em educação que alcançaram nota igual ou superior a cinco na avaliação trienal (2010) da Coordenação de Aperfeiçoamento de Pessoal de Nível Superior (CAPES). Assim, priorizamos as teses e dissertações dos programas de pós-graduação das seguintes instituições: Universidade Estadual de Campinas (UNICAMP), Universidade Federal do Paraná (UFPR), Universidade Federal do Rio Grande do Sul (UFRGS), Universidade do Vale do Rio dos Sinos (UNISINOS), Faculdade de Educação da Universidade de São Paulo (FEUSP), Universidade Federal Fluminense (UFF), Universidade Metodista de Piracicaba (UNIMEP), Universidade 
Federal do Rio de Janeiro (UFRJ), Pontifícia Universidade Católica do Rio de Janeiro(PUC-RJ), Universidade Estadual Paulista "Júlio de Mesquita Filho" campus Marília (UNESP-MAR),Universidade Federal de Goiás (UFG), Universidade Federal de São Carlos (UFSCAR), Universidade Federal de Uberlândia (UFU), Universidade Federal de Minas Gerais (UFMG).

\section{RESULTADOS E/OU DISCUSSÃO}

Na primeira sondagem encontramos 86 produções; destas, 52 dissertações e 34 teses. Das defesas identificadas que tratam especificamente da educação infantil, foram 46 sendo 12 teses e 34 dissertações. Estão distribuídas conforme mostra o gráfico 01.

\section{Gráfico 01}

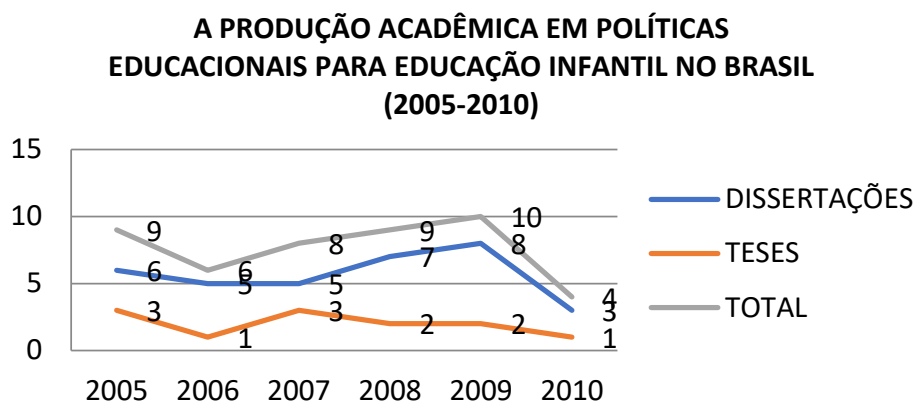

Fonte: Banco de Dados do CEDE. Elaboração própria.

Ao serem organizados por ano de produção, as defesas, teses e dissertações, revelaram que em 2009 houve uma maior quantidade de discussões, contando com 10 produções na área, oscilando nos anos de 2005 e 2008 com 9; 2006 com 6; 2007 com 8; e em 2010 uma brusca queda para 4 produções sobre a presente temática.

A pouca quantidade de produção sobre campo das políticas educacionais na área de educação infantil foi enfatizada por abordagens de autores como Rocha (1999), Rehem (2013), Macêdo e Rehem (2016). Contudo ao comparamos com a quantidade de defesas nos anos de 2000 a 2005, que teve 36 discussões, sendo 25 dissertações e 11 teses, sobre o campo das políticas educacionais para educação infantil, os anos de 2005 a 2010, os quais foram encontradas 46 produções referente a temática em questão, podemos perceber um avanço nas defesas que tem levado em conta a Educação Infantil na agenda política do nosso país.

Na seleção e organização da quantidade existente de teses e dissertações por ano, nos deparamos com a necessidade de expor o quanto as Instituições de Ensino Superior (IES) tem produzido nesta área. O Gráfico 02 abaixo revela a configuração.

Gráfico 02

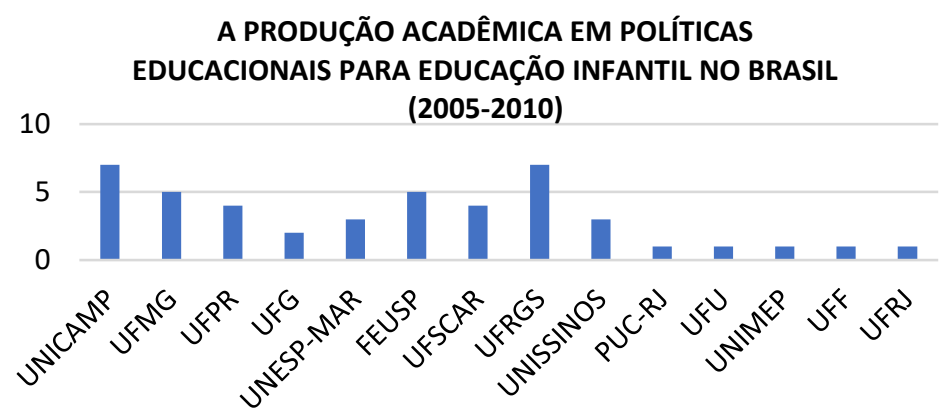

Fonte: Banco de Dados do CEDE. Elaboração própria.

Se levarmos em conta as regiões de localização das IES, as produções estão retidas nas regiões Sudeste (29), Sul (15), Centro-Oeste (2). Assim o Gráfico 03 revela o quadro das produções acadêmicas. 


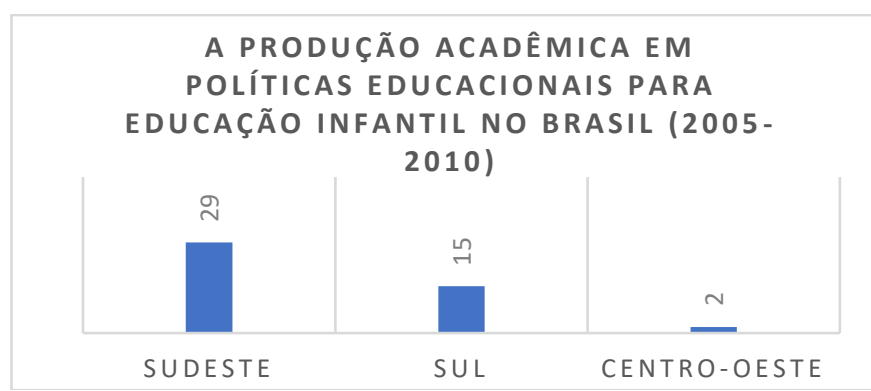

Fonte: Banco de Dados do CEDE. Elaboração própria.

Esta prevalência da produção nas regiões Sudeste e Sul foi revelada na pesquisa anterior, que analisou a produção acadêmica nos anos de 2000 a 2005 no Brasil. Neste ponto nos questionamos quais seriam os fatores que poderiam influenciar a prevalência das produções em uma determinada região do país em detrimento das demais, e principalmente da região Nordeste, que nesta pesquisa aparece nas IES que produziram sobre a temática em questão, sendo que na análise da pesquisa anterior (2000 a 2005) não houve produção na região? Um dos fatores é com relação a importância dada a área de conhecimento, na qual a educação é considerada área P2, de menor importância para as políticas de pós-graduação no Brasil. Outro seria a concentração de recursos, se a Educação é P2, então o recurso destinado à pesquisa nesta área seria também menor. $\mathrm{E}$ um outro seria com relação ao número de cursos e programas, que estariam concentrados nas regiões Sudeste e Sul. Aliado a isto, tem-se que considerar o simbólico nacional, uma carga que tem influenciado para a desconsideração de investimentos na região Nordeste e Norte do nosso país, como aponta Silva (2016).

$\mathrm{Na}$ análise dos resumos nos detemos na forma de abordagem presentes nas pesquisas, se estão focando o contexto teórico prático ou o contexto político. Conforme exposto no Gráfico:

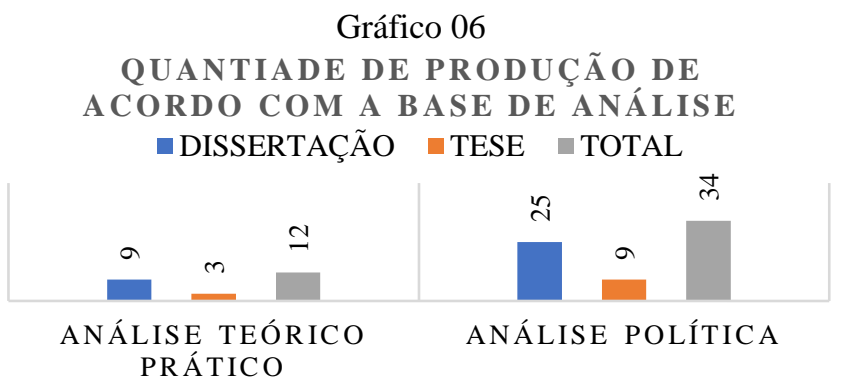

Fonte: Banco de Dados do CEDE. Elaboração própria.

As teses e dissertações priorizaram a abordagem de análise das políticas educacionais, diferente do quadro observado na pesquisa realizada entre os anos de 2000 a 2005 na qual foram encontradas 24 produções que se debruçaram sobre o contexto teórico prático, contra 12 produções sobre o contexto político, bem como exposto pelas autoras Rocha (1999), Arretche (2003), Rehem (2013), Silva e Jacomini (2016, p.10), que nas suas pesquisas revelaram a prevalência do confronto teórico prático das políticas educacionais.

Como as políticas surgem das demandas da sociedade, bem como a produção acadêmica, fatores como o crescimento das teses e dissertações sobre as questões das políticas educacionais voltadas para educação infantil em nosso país, apontam a necessidade de aprofundamento nas leituras das discussões de forma crítica da abordagem teórico metodológico presente nos textos acadêmicos.

\section{CONSIDERAÇÕES FINAIS}

No aspecto analítico das produções acadêmicas as regiões que apresentaram maior quantidade foram Sudeste e Sul, conforme quadro revelado na pesquisa sobre a 
produção acadêmica em políticas educacionais para educação infantil no Brasil nos anos de 2000 a 2005, bem como outras pesquisas realizadas pelas autoras Rocha (1999), Rehem (2013), Macêdo e Rehem (2016).

As análises realizadas demonstram a configuração das produções em termos de quantidade sendo encontrados 46 trabalhos sobre o presente campo, teses:12 e dissertações:34, no período de 2005 a 2010 nos cursos de pós-graduação, das quais a maioria dos trabalhos se debruçou sobre a análise do contexto político. Quando comparado com os anos de 2000 a 2005, na qual o quadro revelado foi de 36 discussões, sendo dissertações: 25 e teses:11, em que a maioria dos trabalhos se debruçou sobre o contexto teórico prático das políticas. A pouca quantidade de produção no campo das políticas educacionais para educação infantil ainda é muito forte, por isso destacamos a importância das pesquisas denominadas estado da arte devido ao alcance em apontar lacunas.

Consideramos o trabalho de grande relevância tanto para a constituição do campo de discussão voltado para Políticas educacionais para Educação Infantil quanto para ampliar a discussões em torno da tendência das pesquisas nos programas de pósgraduação do nosso país.

\section{REFERÊNCIAS}

ARCE, Alessandra. Compre o Kit Neoliberal para a Educação Infantil e ganhe grátis os dez passos para se tornar um professor reflexivo. In: Educação\& Sociedade, ano XXII, $\mathrm{n}^{\mathbf{0}} \mathbf{7 4}$, Abril/2001.

ARRETCHE, Marta. Dossiê agenda de pesquisa em políticas públicas.In:RBCS Vol.18, $\mathrm{n}^{\mathrm{o}} .51$, fevereiro-2003.

FERRIERA, Norma Sandra de Almeida. As pesquisas denominadas "Estado da Arte".In: Educação \& Sociedade, ano XXIII, nº 79, p. 257-272, Agosto/2002.

GATTI, Bernadete A. Implicações e perspectivas da pesquisa educacional no Brasil contemporâneo. In: Cadernos de Pesquisa, n. 113, p. 65-81, julho/2001.

KUHLMANN JUNIOR, Moysés. Infância e educação infantil: uma abordagem histórica. Porto Alegre: Mediação, 1998, p.197- 2009.

PENN, Hellen. Primeira Infância: A visão do Banco Mundial. In:Caderno de Pesquisa $n^{\circ}$ 115, p.7-24, mar/2002. Tradução de Fúlvia Rosemberg.

REHEM, Faní Quitéria Nascimento. "Coisa de pobre": A política de educação infantil em Feira de Santana - Bahia (2001-2008). Tese de Doutorado. Brasília: UNB, 2013.<http://repositorio.unb.br/bitstream/10482/15047/1/2013_FaniQuiteriaNascimentoRehem. pdf acesso em 28 Janeiro de 2016.

ROCHA, Eloisa A. C. A pesquisa em Educação Infantil no Brasil: trajetória recente e perspectivas de consolidação de uma pedagogia. (Tese de doutorado),FAE/UNICAMP, 1999. ROSEMBERG, Fúlvia. Organizações Multilaterais, Estado e Políticas de Educação Infantil. In: Cadernos de Pesquisa, n. 115,março/2002.

SHIROMA, Eneida Oto; CAMPOS, Roselane Fátima; GARCIA, Maria Cardoso. Decifrar textos para compreender a política: subsídios teórico-metodológicos para análise de documentos. In: PERSPETIVA, Florianópolis, v. 23, n. 02, p. 427-446, jul./dez. 2005.

SILVA, Antonia Almeida. Pesquisa e Pós-graduação em Educação no Nordeste: entre os enlaces do passado e a construção de novos simbólicos nacional/regional. In: Caminhos da pós-graduação em educação no nordeste do Brasil: avaliação, financiamento, redes e produção científica. Maria Vilani Cosme de Carvalho, Josania Lima Portela Carvalhedo, Francisco Antonio Machado Araújo, organizadores. - Teresina: EDUPI, 2016.

SILVA, Antônia Almeida; JACOMINI, Márcia Aparecida, organizadoras. Pesquisa em políticas educacionais: características e tendências. - Feria de Santana: UEFS Editora, 2016. 